ORIGINAL ARTICLE

\title{
Shyness, self-presentation, adonization, and influence tactics in close relationships
}

\author{
Eugenia Mandal ${ }^{A, B, C, D, E, F}$, Aleksandra Wierzchoñ ${ }^{A, B, C, D, E, F}$ \\ Institute of Psychology, University of Silesia, Katowice, Poland
}

\section{BACKGROUND}

Empirical research reveals the difficulties that shy people must face as part of their social functioning and attaches a pejorative connotation to shyness in the process of establishing and maintaining interpersonal relations. The purpose of the study was to investigate certain aspects of social functioning of shy people: the preferred self-presentation styles, readiness to adopt adonization and influence tactics in intimate relationships.

\section{PARTICIPANTS AND PROCEDURE}

The study was performed on a group of 234 participants (113 females and 121 males), aged 18 to 35 years $(M=24.29)$. The following questionnaires were used: the Revised Cheek and Buss Shyness Scale, the Self-Presentation Questionnaire, the Questionnaire for Measuring the Attitude toward Adonization, and the Influence in Close Relationships between Women and Men Questionnaire.

\section{RESULTS}

The study found that shy people use self-promotion less frequently than non-shy persons and they tend to adopt self- depreciation more often compared to non-shy individuals. Further, a high level of shyness implies a less pronounced tendency to use adonization but a greater readiness to employ hard social influence tactics in close relationships: Threats and violence, Silent treatment and sulking and Complaining and arguing.

\section{CONCLUSIONS}

Correlations between shyness, self-presentation styles, adonization and influence tactics in close relationships emphasize the role of this disposition in generating social behaviors. Shyness has a negative impact on an individual's social functioning and relations with other people. The negative consequences of shyness are particularly conspicuous in the behavior of men.

\section{KEY WORDS}

shyness; close relationships; social influence

CORresponding Author - Prof. Eugenia Mandal, Institute of Psychology, University of Silesia, 53 Grażyńskiego Str., 40-126 Katowice, Poland, e-mail: eugenia.mandal@us.edu.pl

AUthors' CONTRIBUtion - A: Study design - B: Data collection - C: Statistical analysis - D: Data interpretation .

E: Manuscript preparation · F: Literature search · G: Funds collection

to Cite this ARTICLE - Mandal, E., \& Wierzchoń, A. (2019). Shyness, self-presentation, adonization, and influence tactics

in close relationships. Current Issues in Personality Psychology, 7(3), 189-202.

RECEIVED 27.04.2019 • REVIEWED 21.08.2019 • ACCEPTED 05.09.2019 • PUBLISHED 27.09.2019 


\section{BACKGROUND}

The pervasiveness of the epithet shy demonstrates how relevant it proves to be as a category of the description of an individual's functioning. The abundance of textbook definitions of shyness may pose certain conceptual difficulties. Shyness is a heterogeneous notion (Zimbardo, 1994).

Source literature covers two complementary manners of presenting shyness - the syndromal and dispositive perspectives. The syndromal presentation of shyness is illustrated in a study by Cheek and Watson (1989), where they asked the subjects the question "How do you know you are shy?". The provided answers fell into the categories of three components making up a three-component model of shyness. Identification of shyness requires experiencing the symptoms belonging to at least one of the components.

The behavioral aspect of shyness evolves around the concept of reduced verbal and non-verbal activity in public situations. Pilkonis (1977a) presented characteristics of a shy person, whose interpersonal communication differs from the communication established by confident people both in the quantitative and qualitative aspects. Shyness involves difficulties in initiating and maintaining an interaction. A substantially smaller number of utterances can be observed as well as stiffness, lack of comfort and a greater number of moments of awkward silence (Asendorph, 1988; Zimbardo, 1994). Also distancing behaviors, e.g. limited eye contact, can be observed (Pilkonis, 1977a).

Considering the cognitive aspects of shyness, well-developed public and private self-awareness must be emphasized. Shy individuals will focus excessively on how they are perceived by others and how they experience themselves in situations of social exposure. Shy people divert attention away from their interlocutors and focus it on themselves (Pilkonis, 1977b; Zimbardo, 1994).

It is the somatic-affective component of shyness that fully conveys the concept of social anxiety. It is the tension heightened by being in the company of other people, caused by the conviction of being judged by them (Leary \& Kowalski, 2001). Amongst the most distinctive physiological symptoms of shyness are a quickened pulse, increased perspiration and the characteristic blush (Zimbardo, Pilkonis, \& Norwood, 1974; Zimbardo, 1994).

The dispositive perspective, when integrating the described manifestations of shyness, seems necessary on the definition level. According to this perspective, it is assumed that shyness constitutes a relatively permanent tendency to feel tension in actual or envisaged interpersonal encounters, while manifesting itself at the same time in other areas of functioning behavioral and cognitive (Cheek \& Briggs, 1990). The circumstances that generate the expression of shyness encompass, among others, being the center of attention, large groups of people and social situations in the broad sense, including contacts with strangers, people of the opposite sex, authorities and even friends and relatives (Zimbardo, 1994).

As opposed to situational shyness, dispositional shyness provides a wider spectrum of situations that trigger it as well as a greater intensity and permanence of the reaction (Zimbardo et al., 1974). For the sake of differentiation it may be assumed that dispositional shyness includes the anticipation of embarrassment (Asendorph, 1990). It has to be noted that shyness is a dimension of normal functioning and over $80 \%$ of shy people do not meet the criteria for social phobias. Such a diagnosis is, however, indeed more frequent in this population (Heiser, Turner, \& Beidel, 2003). Shyness as an independent personality dimension is, moreover, not to be considered identical to introversion or neuroticisms (Crozier, 1979).

The persistent increasing tendency pertaining to experiencing chronic shyness, declared by as much as $50 \%$ of adults (Henderson, Zimbardo, \& Carducci, 2001), as well as the self-proclamations of dispositional shyness at a given moment in life by over $80 \%$ of subjects (Zimbardo et al., 1974), demonstrates the prevalence and problematic nature of the examined phenomenon. Despite the attempts at a valorization of shyness that accentuates its role in the process of self-development (Harwas-Napierała, 1995) and a careful selection of interaction partners (Zimbardo, 1994), shyness remains a phenomenon with negative connotations, particularly on the level of interpersonal relations.

The latest research has provided substantial input into psychological knowledge as far as essential shyness correlates are considered. Contrary to the common stereotype of a shy female, males experience shyness equally often. However, its external manifestations, e.g. blush, tend to be less clear to observe. One crucial differentiating factor for the group of shy people has proved to be gender. It is people who are psychologically characterized as masculine and androgynous who experience shyness less frequently and less acutely (Bruch, Berko, \& Haase, 1998; Mandal, 2008a).

Shyness correlates moderately positively with loneliness, negative affect and depression, while correlating negatively with self-esteem. Shy people demonstrate a lower level of emotional intelligence (Hajloo \& Farajian, 2013). Shyness can create a barrier to assertive behaviors (Bratko, Vukosav, Zarevski, \& Vranić, 2002). As its quintessence one may consider social competence deficits and fear of rejection (Jackson, Towson, \& Narduzzi, 1997).

The psychological functioning of a shy person may be reflected on the social level. Shy people are 
more likely to work in jobs for which they are overqualified and they have trouble finding a romantic partner (Van Zalk, Lamb, \& Rentfrow, 2017). Shy individuals tend to derive less satisfaction from their friendship relations (Ponti \& Tani, 2015). A study of romantic relationships formed by shy people yielded corresponding results in terms of a lower level of relationship satisfaction (Tackett, Nelson, \& Busby, 2013). Shy individuals experience the sense of social bonds to a lesser degree and tend not to feel sufficiently supported by others (Dzwonkowska, 2003). Shyness is a trait that takes a heavy toll on the social behaviors of any individual.

The notion of self-presentation, originally explored within the context of humanistic sociology, has expanded its presence in psychological literature as expression of behaviors directed at revealing aspects of the self. The forming of an image serves various functions: it facilitates communication (Goffman, 1959), constitutes a source of information regarding a person's identity (Tice, 1992), helps regulate emotions (Baumgardner, Kaufman, \& Levy, 1989) or guarantees personal advantages (Jones \& Pittman, 1982). These goals are achieved through assertive or defensive self-presentation. Assertiveness of selfpresentation is connected with an open demonstration of an individual's virtues, whereas its defense consists in avoiding the self-presentation risk. People who present themselves defensively do not want to be perceived in a negative manner but at the same time do not expose their advantages for fear of rejection and loss of security (Baumeister, Tice, \& Hutton, 1989). A contrasting typology of self-presentational behaviors concentrates on their intentionality. In a broad sense, self-presentation is regarded as a continuous action that does not necessarily have to be performed consciously. By contrast, self-presentation in a narrow sense defines the behavior as intentionally designed with the aim of obtaining certain benefits and/or of minimizing potential losses (Schlenker \& Weigold, 1992).

The consequence of the outlined issue is the typification of self-presentation that encompasses selfpromotion and self-depreciation (Leary, 2012). The former consists in presenting accomplishments and values of an individual, while the latter is the action that belittles his or her value by emphasizing lack of competence and weaknesses. It has been hypothesized that every person may be characterized in the context of inclination towards actions connected with the first or the second type.

It has been proven that a high self-esteem predisposes to a more boastful self-presentation, whereas a lower one predisposes to a defensive self-presentation (Baumeister et al., 1989). Self-promotion is connected with better interpersonal and intrapersonal adjustment (Dufner et al., 2012). Self-depreciation, on the other hand, inspires negative feelings on the ob- servers' side, causing an obligation for them to show support (Leary, 2012).

Buss and Briggs (1984), when emphasizing the role of personality in the employment of self-presentation, invoke shyness, among other factors. Schlenker and Leary (1982) attribute key importance to self-presentation as regards understanding the basis for social fear. In their considerations, they suppose that the individuals who experience social fear more intensely are those who are convinced of their incapability to create a positive impression upon others. This group is, at the same time, highly motivated to create a desired image. The researchers argue that the employment of self-presentation increases social fear per se; hence, an individual is more likely to make an effort to create a desired image when he or she has a strong need for positive feedback from society and consequently, by employing self-presentation, those persons experience greater social fear and must face the risk of rejection. Social fear and self-presentation remain mutually dependent.

Studies on exerting social influence grant people who are physically attractive interpersonal power. This is best put in a statement by Laura C. Longo and Richard D. Ashmore (1992): "what is beautiful is good - at getting others to do what (s)he wants". Good looks correspond with the effectiveness of having an impact on others. This dependency would have been accounted for by remarkable communication skills (Chaiken, 1979). Such interpretations rely on the notion of the halo effect, according to which attractive people are more likely to be perceived as possessing a number of admirable traits, such as politeness and sociability (Dion, Berscheid, \& Walster, 1972). Such being the case, physical attractiveness is treated as a universal self-presentation motive (Leary et al., 1994). Being considered attractive, referred to as adonization, increases the probability of achieving one's goals.

Adonization was originally considered within the context of self-presentational behaviors - either as a purpose or as a strategy of self-presentation. It emerges that creation of image of an attractive person is stronger in the circumstance of potential gain, particularly towards the opposite sex, whereas it is weaker in the circumstance of a potential loss (Mandal, 2003). As a result of the conducted empirical studies, the definition of adonization has been transformed. Its etymology, however, has remained unchanged and triggers associations with the mythological figure of Adonis, the symbol of ideal masculine beauty (Mandal, 2003, 2008b).

Currently, the concept of adonization goes beyond the confines of the theory of self-presentation. Adonization is understood as an attitude towards appearance and its role in the social world. Its cognitive component is a dual system of beliefs. The first set of beliefs concerns the issue of the overall meaning of 
physical attractiveness in the world, while the second group includes self-evaluation of a person's appearance and the potential to use it in order to gain personal benefits. The emotional component includes the emotional attitude towards behaviors connected with adonization. The motivational component, on the other hand, relates to the actions that are actually taken.

Studies show interpersonal differences when susceptibility to adonization is concerned. The primary personal predispositions that have been identified are narcissism, Machiavellianism and pragmatism (the tendency to monitor one's self-presentation). At the same time, the motivational component of adonization is positively correlated with psychological masculinity, since men display a stronger tendency, by and large, to adopt behaviors characteristic of adonization, compared to women. Certain age discrepancies have also been noted. Among adults, the age group 18 to 30 presents a more positive attitude to adonization (Mandal, 2008b, 2014a). Taking advantage of one's beauty in a deliberate manner proves to have positive social consequences. Individuals who employ this strategy are perceived as more proactive and feeling a stronger sense of community, especially when they direct their behavior at the opposite sex and when they are indeed physically attractive (Mandal, Latusek, \& Moroń, 2015).

Power constitutes a paramount element of the social space. Its determinants are multidimensional. Some of the key personal determinants of power are stereotypically masculine traits (Mandal, 2012). Males are fundamentally more influential than females in terms of gender, except for activities that are stereotypically feminine (Carli, 2001). The holding of power strengthens the ability to exert an impact on others. Social impact is a process of multidimensional changes occurring in an individual or in a group of people under the influence of the real or imaginary presence of other people. It may be exerted intentionally or unintentionally and it is evolutionarily conditioned (Sundie, Cialdini, Griskevicius, \& Kenrick, 2012). People in power tend to implement more direct and rational influence tactics, whereas being in a subordinate position frequently implies indirect and irrational approaches (Falbo, 1977).

Power in an intimate relationship is specific and multidimensional in its nature. Research conducted by Felmlee (1994) shows that $46.1 \%$ of a sample group of 413 people who were in a close relationship at the time declared a symmetrical distribution of power, while greater power is much more frequently attributed to males. At the same time, the manner in which men execute their power is more direct than the techniques that are likely to be chosen by females.

Apart from the perspective of gender, the determinants of power in an intimate relationship are considered from the viewpoint of cultural factors, e.g. gender roles and stereotypes, individual factors, e.g. the owned resources, emotional involvement or mental qualities of the partners, as well as the nature of the relationship itself, e.g. the quality of the relation. Further, power in a relationship remains dependent on the activities and responsibilities of the partners involved in it. Among the most significant predictors of power in a relationship are its longevity and character (formalized/not formalized). What needs to be taken into account here is also whether the impact exerted on another person has negative or positive consequences (Mandal, 2008b).

Exerting an impact on a partner in a close relationship is a complex phenomenon and, due to the nature of a romantic relationship, dynamic. Howard, Blumstein and Schwartz (1986) in a study that involved 235 homosexual and heterosexual couples made the distinction between three groups of influence tactics in an intimate relationship: weak tactics: Manipulation (making allusions, seducing, mentioning past favors) and Supplication, neutral tactics: Disengagement and Bargaining and strong tactics: Bullying and Autocracy (using one's own authority and power). Research has established a connection between weak tactics and a lower position of power in a relationship on the one hand and strong tactics and a higher position of power on the other. No correlations with the gender of the person who exerts power have been revealed, except for the Disengagement technique, which is indeed more frequently applied by males. The technique that has been proven to be used by partners most often was Bargaining, whereas Bullying tended to be adopted the fewest times.

The vast majority of studies on exerting influence in close relationships focus on the exploration of the meaning of personality. The personality of the person who uses his or her influence over another person plays a more substantial role in the context of holding power in a relationship than the personality of the individual who is under the influence of that person. Buss (1992) found that neuroticism constitutes a predictor of adopting tactics that have a displeasing impact on the recipient (Silent treatment, Self-depreciation, Compulsion, Regression), whereas extraversion and psychoticism are predictors of taking advantage of an individual's personal charm, and extraversion and conscientiousness are predictors of Persuasion.

Taking into account the interaction factor, Sijko (2008) performed analyses of dialogs of 25 couples on controversial issues they were facing within their relationships, observing the symmetry of the partners' behaviors. Women who exerted influence using soft tactics activated those same weak tactics in men, while women who employed hard influence techniques triggered hard behaviors in their male partners. Only men who adopted hard tactics generated disengaging behaviors in their female partners. 
Hard tactics are typical of unhappy marriages and correlate negatively with marital satisfaction (Mandal, 2008b). In light of the review of the psychological literature presented above, there arises the question of the role of shyness in self-presentation, predisposition to adonization and preference of employing influence tactics in intimate relationships.

The adopted theoretical determinations lead to the following research hypotheses.

It was assumed that due to low self-esteem (Crozier, 1981), shy persons are less likely to employ selfpromotion and tend to use self-depreciation towards themselves more frequently compared to non-shy people.

Taking into consideration social fear (Leary \& Kowalski, 2001) and behavioral inhibitions that are ascribed to shy people (Pilkonis, 1977a), it has also been supposed that shy people would adopt adonization much less frequently than non-shy individuals.

Furthermore, it has been hypothesized that shy people, due to their potentially lower power position in close relationships (Mandal, 2008b, 2012) or the fact that they tend to be more unassertive (Bratko et al., 2002), are more likely to use soft and indirect influence tactics. They employed hard tactics significantly less often than non-shy persons.

The research was carried out in order to ascertain whether shy individuals differ from non-shy persons in terms of styles of self-presentation, the tendency to employ adonization and influence tactics in intimate relationships. In view of the role of shyness in generating social behaviors, as it is detailed in the subject literature, certain differences were expected to arise between individuals with higher and lower intensity of the examined disposition in terms of activity in social space.

The verification of the formulated hypotheses was designed for a group of young adults aged 18 to 35 . The developmental tasks ascribed to young adults include obtaining and maintaining a job and establishing a romantic relationship and getting married (Brzezińska, Appelt, \& Ziółkowska, 2016). It may be assumed that high effectiveness of social influence is essential to succeed in those tasks. At the same time, the review of research consistently demonstrates the obstacles shy people encounter when pursuing the goals mentioned above (Zimbardo, 1994; Carducci, 2008).

\section{PARTICIPANTS AND PROCEDURE}

\section{PARTICIPANTS}

A total of 234 participants were enrolled in the study (113 females and 121 males) aged 18 to $35(M=24.29$, $S D=4.37)$. Among those, there were participants who completed secondary education (36\%, i.e. 84 individuals), higher education (33\%, i.e. 78 participants) and participants with incomplete higher education $(22 \%$, i.e. 51 participants). The majority of the participants lived in towns with more than 100000 inhabitants (41\%, i.e. 96 individuals) or fewer than 100000 inhabitants (29\%, i.e. 67 participants), while $30 \%$, i.e. 71 participants, were rural inhabitants. $51 \%$ of the research group were students and $49 \%$ were not studying at the time. 79 participants declared they were single, 119 respondents were in an informal relationships of medium length $M=2.91$ years, $S D=2.15$, and 36 people were married and in medium length marriages $M=6.83$ years, $S D=3.90$.

\section{DATA COLLECTION}

Participants of the study were selected using the snowball sampling method. The survey was designed for individual completion. Participants filled out a set of questionnaires after giving consent to participate in the study. They were informed of the purpose of the study, they learnt it would be voluntary and anonymous and that the obtained results would be confidential.

\section{RESEARCH MEASURES}

Shyness. The tool that was used to measure dispositional shyness, whose manifestations take the form of behavioral implications of tension that is intensified in other people's presence, was the unifactorial Revised Cheek and Buss Shyness Scale (RCBS; Cheek, 1983; Hopko, Stowell, Jones, Armento, \& Cheek, 2005; Polish adaptation of Mandal \& Wierzchoń, 2018). It comprises 13 statements that are addressed by the respondents on a 5 -point scale ranging from 1 (strongly disagree) to 5 (strongly agree) with the reliability $\alpha=.86$ (in the conducted study $\alpha=.87$ ). The higher the score, the greater the intensification of a particular variable. To illustrate: "It is hard for me to act naturally when I am meeting new people"; "I feel inhibited in social situations". Considering the research issues that made it necessary to differentiate between individuals whose levels of shyness were either high or low, the distinctive criterion of $1 / 2$ of the standard deviation of the average score in the sample, i.e. 32.50 (for results $\min =13$ and $\max =58$ ) was adopted. The participants who were enrolled in the study were respectively 78 non-shy individuals (39 females and 39 males) with scores ranging from 13 to 27 and 66 shy persons (33 females and 33 males), whose results ranged between 38 and 58 points.

Self-presentation. The tendency to use certain forms of tactical self-presentation behaviors was examined using the Self-Presentation Questionnaire (Wojciszke, 2002). It is a 30-item tool comprising the Self-promotion Scale (example statement: "I embrace 
my merits") and the Self-depreciation Scale (example statement: "I avoid talking about my success"). The answers are provided on a scale from 1 (never) to 5 (very often). The tool is associated with satisfactory reliability: $\alpha=.87$ for the Self-promotion Scale (in the conducted study $\alpha=.83$ ) and $\alpha=.79$ for the Selfdepreciation Scale (in the conducted study $\alpha=.80$ ).

Adonization. The questionnaire for measuring the attitude toward adonization - Scale A (Mandal \& Winkler, 2005) is available in two versions, one for men and one for women. It consists of 20 statements that require responses on a 7-level scale from 1 (strongly disagree) to 7 (strongly agree), producing results ranging from 20 points (a slight tendency to employ adonization) to 140 points (a strong inclination to use adonization). In addition to the overall score, the tool allows interpretation of the results under the following subscales: the cognitive attitude component, measured using two groups of convictions ( $1^{\text {st }}$ group of convictions, 2 positions, e.g. "When you take advantage of your appearance skillfully, you can achieve anything" and the $2^{\text {nd }}$ group of convictions, 5 positions, e.g. "I can make the most of the way that I look to make it my greatest advantage"), affective attitude component (6 positions, e.g. "I like flirting") and a motivational attitude component (7 positions, e.g. "I would use the fact that my boss finds me attractive to get a promotion"). The test's reliability for the overall score varies around $\alpha=.91$ (in the conducted study $\alpha=.94$ ).

Influence tactics in close relationships. For the purpose of the study the Influence in Close Relationships between Women and Men Questionnaire (Mandal, 2014b) was administered. The instrument contains 35 statements that require responding according to a 7-level scale, where 1 states $I$ never do this, and 7 states I'm very willing to do this. The questionnaire includes 10 subscales. The mean score obtained by a respondent determines his or her tendency to behave towards the partner in a relationship in a manner described in the subscale. At the same time, it describes a person's behavior in an intimate relationship when the application of hard, middle or soft tactics is concerned. Hard tactics include the following techniques: Threats and violence (6 positions, e.g. "I slap him/her in the face"), Complaining and arguing (3 positions, e.g. "I get angry and I yell at my partner") and Silent treatment and sulking (5 positions, e.g. "I stop talking to my partner and after some time has passed, I take the issue up again"). The middle tactics are covered by the subscales: Persuasion and persistence (4 positions, e.g. "I never let go, I will try to persuade my partner until he/she finally agrees"), Argumentation and making requests (3 positions, e.g. "I ask him/her"), Partner's authority ( 2 positions, e.g. "I tell my partner that she/he should do it, since she/he would be better at it as a woman/man") and One's own authority (2 po- sitions, e.g. "I say that I'm better at it than her/him"). Soft tactics include the following: Bartering and favors (4 positions, e.g. "I give my partner a gift prior to asking him/her to do something"), Romanticism and surprises (3 positions, e.g. "I am nice and volunteer to do things that I normally would not be willing to do") and Incompetence and hugging (3 positions, e.g. "I act like I am a bit lost and clumsy to get my partner to do what I want her/him to do"). The reliability for each of the subscales ranges between $\alpha=.86$ (Threats and violence) and $\alpha=.58$ (One's own authority), while for the overall coefficient $\alpha=.89$ (in the conducted study $\alpha=.91$ ).

\section{RESULTS}

The results have shown that in terms of self-presentational behaviors, shy persons indeed employ selfdepreciation more often $(M=45.97)$ than non-shy persons $(M=37.53, p<.001)$. Shy people scored lower on the self-promotion scale $(M=41.80)$ compared to non-shy people $(M=46.14, p<.001)$. In comparison with non-shy individuals $(M=70.54)$, inhibited participants are less likely to use adonization $(M=57.11$, $p=.004)$. Further, shy people obtained lower scores on the adonization scale that examined the cognitive component $(M=21.08)$ compared to the reference group $(M=26.63, p<.001)$, emotional component $(M=17.21)$ compared to the reference group $(M=21.40, p=.006)$ and motivational component $(M=17.79)$, demonstrating a substantially lower readiness to adopt behaviors associated with adonization as compared with the non-shy participants $(M=21.76, p=.024)$ (Table 1$)$.

Shy individuals tend to use hard influence techniques substantially more frequently $(M=2.45)$ than non-shy persons $(M=2.12, p=.045)$. Shy participants $(M=1.57)$ are inclined to use Threats and violence more often than non-shy persons $(M=1.36, p=.006)$. Additionally, the inhibited participants demonstrate a greater readiness to employ Silent treatment and sulking $(M=2.49)$ than the non-shy persons $(M=2.16, p=.087)$ and to use Complaining and arguing $(M=3.28)$ more often than uninhibited individuals $(M=2.85, p=.098)$. In terms of soft and neutral tactics, it has been observed that shy individuals are less likely to engage in Argumentation and making requests $(M=5.07)$ when compared to uninhibited people $(M=5.63, p=.006)$ (Table 2$)$.

Shy women adopt self-depreciation $(M=47.97)$ more often than non-shy women $(M=38.54, p<.001)$. What is more, the inhibited women $(M=41.85)$ exhibit a less pronounced tendency to use self-promotion in comparison to non-shy women $(M=45.74$, $p=.024)$. It was found that the level of shyness does not differentiate the female group in terms of the tendency to use adonization (Table 3 ). 
Eugenia Mandal, Aleksandra Wierzchoń

Table 1

Self-presentation styles and inclination to adopt adonization as characteristic of shy and non-shy persons

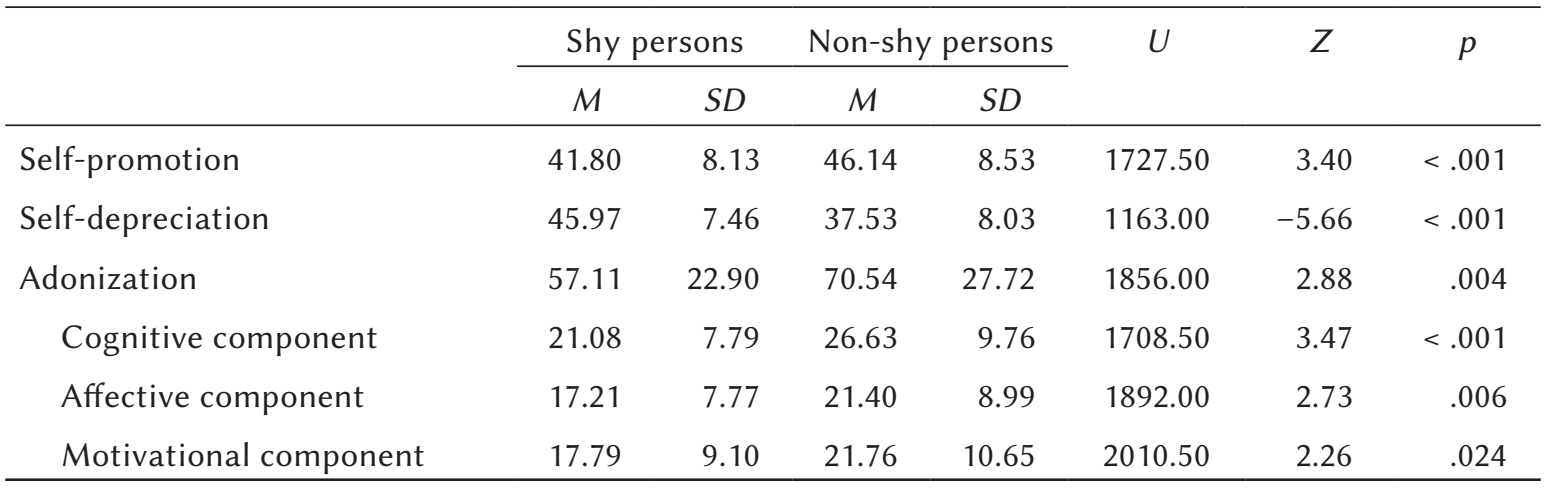

Note. A parametric $t$-test performed for variables characterized by normal distribution yielded identical results.

Table 2

Influence tactics in close relationships of shy and non-shy persons

\begin{tabular}{|c|c|c|c|c|c|c|c|}
\hline & \multicolumn{2}{|c|}{ Shy persons } & \multicolumn{2}{|c|}{ Non-shy persons } & \multirow[t]{2}{*}{$U$} & \multirow[t]{2}{*}{$Z$} & \multirow[t]{2}{*}{$p$} \\
\hline & $M$ & $S D$ & $M$ & $S D$ & & & \\
\hline Soft tactics & 3.80 & 0.91 & 3.65 & 1.04 & 2297.50 & -1.11 & .268 \\
\hline Incompetence and hugging & 3.64 & 1.64 & 3.23 & 1.63 & 2169.00 & -1.63 & .104 \\
\hline Bartering and favors & 3.33 & 1.08 & 3.20 & 1.25 & 2298.00 & -1.11 & .268 \\
\hline Romanticism and surprises & 4.43 & 1.30 & 4.53 & 1.24 & 2452.00 & 0.49 & .625 \\
\hline Medium tactics & 3.99 & 1.06 & 4.19 & 1.06 & 2342.50 & 0.93 & .354 \\
\hline One's own authority & 3.42 & 1.47 & 3.40 & 1.63 & 2521.50 & -0.21 & .834 \\
\hline Partner's authority & 3.56 & 1.50 & 3.65 & 1.85 & 2534.00 & 0.16 & .873 \\
\hline $\begin{array}{l}\text { Argumentation and making } \\
\text { requests }\end{array}$ & 5.07 & 1.31 & 5.63 & 1.15 & 1889.00 & 2.76 & .006 \\
\hline Persuasion and persistence & 3.91 & 1.26 & 4.06 & 1.27 & 2373.50 & 0.80 & .422 \\
\hline Hard tactics & 2.45 & 1.04 & 2.12 & 0.90 & 2072.50 & -2.01 & .045 \\
\hline Silent treatment and sulking & 2.49 & 1.18 & 2.16 & 1.14 & 2149.00 & -1.71 & .087 \\
\hline Complaining and arguing & 3.28 & 1.60 & 2.85 & 1.47 & 2162.50 & -1.65 & .098 \\
\hline Threats and violence & 1.57 & 0.86 & 1.36 & 0.66 & 1907.50 & -2.75 & .006 \\
\hline
\end{tabular}

Note. A parametric $t$-test performed for variables characterized by normal distribution yielded identical results.

Table 3

The self-presentation styles and the tendency to adopt adonization as ascribed to shy and non-shy women

\begin{tabular}{|c|c|c|c|c|c|c|c|}
\hline & \multicolumn{2}{|c|}{ Shy women } & \multicolumn{2}{|c|}{ Non-shy women } & \multirow[t]{2}{*}{$U$} & \multirow[t]{2}{*}{$Z$} & \multirow[t]{2}{*}{$p$} \\
\hline & $M$ & $S D$ & $M$ & $S D$ & & & \\
\hline Self-promotion & 41.85 & 7.94 & 45.74 & 8.12 & 443.50 & 2.26 & .024 \\
\hline Self-depreciation & 47.97 & 6.10 & 38.54 & 7.42 & 192.50 & -5.10 & $<.001$ \\
\hline Adonization & 55.88 & 25.16 & 63.90 & 24.84 & 508.00 & 1.53 & .127 \\
\hline Cognitive component & 21.85 & 8.52 & 24.69 & 9.20 & 517.00 & 1.43 & .154 \\
\hline Affective component & 16.39 & 8.53 & 18.82 & 8.16 & 533.50 & 1.24 & .215 \\
\hline Motivational component & 16.76 & 9.27 & 19.74 & 9.10 & 501.00 & 1.61 & .108 \\
\hline
\end{tabular}

Note. A parametric $t$-test performed for variables characterized by normal distribution yielded identical results. 
In close relationships, shy women $(M=2.70)$ tend to use hard influence tactics more often than non-shy women $(M=2.25, p=.044)$. Shy women are more likely to adopt the Complaining and arguing tactic $(M=3.73)$ in comparison to non-shy women $(M=2.95, p=.029)$, as well as the Threats and violence tactic $(M=1.45)$ when compared to non-shy women $(M=1.38$, $p=.054)$. Further, shy women $(M=2.91)$ scored higher than non-shy women $(M=2.43, p=.078$, non-significant) on Silent treatment and sulking (Table 4).

In the group of men, the analyses revealed substantial differences in the preferred self-presentation styles. Shy men employ self-promotion significantly less frequently $(M=41.76)$ than non-shy men
$(M=46.54, p=.012)$. Further, the implementation of self-depreciation is considerably more likely to occur for shy men $(M=43.97)$ when compared to non-shy men $(M=36.51, p<.001)$. Moreover, the readiness to adopt adonization is less pronounced for shy men $(M=58.33)$ in comparison to the group of non-shy men $(M=77.18, p=.006)$. The shy men score substantially lower on the scale measuring the cognitive component $(M=20.30)$, compared to non-shy men $(M=28.56, p<.001)$, the affective component $(M=18.03)$ in comparison to non-shy men $(M=23.97$, $p=.005)$ and the motivational component $(M=18.82)$ compared to non-shy men $(M=23.77, p=.093$, nonsignificant) (Table 5).

Table 4

Influence tactics in close relationships of shy and non-shy women

\begin{tabular}{|c|c|c|c|c|c|c|c|}
\hline & \multicolumn{2}{|c|}{ Shy women } & \multicolumn{2}{|c|}{ Non-shy women } & \multirow[t]{2}{*}{$U$} & \multirow[t]{2}{*}{$Z$} & \multirow[t]{2}{*}{$p$} \\
\hline & $M$ & $S D$ & M & $S D$ & & & \\
\hline Soft tactics & 3.90 & 0.97 & 3.78 & 1.06 & 611.00 & -0.36 & .718 \\
\hline Incompetence and hugging & 4.15 & 1.30 & 3.58 & 1.73 & 506.00 & -1.55 & .120 \\
\hline Bartering and favors & 3.32 & 1.04 & 3.23 & 1.20 & 596.00 & -0.53 & .594 \\
\hline Romanticism and surprises & 4.23 & 1.36 & 4.54 & 1.16 & 560.50 & 0.94 & .349 \\
\hline Medium tactics & 4.11 & 0.94 & 4.14 & 1.18 & 614.00 & 0.33 & .743 \\
\hline One's own authority & 3.48 & 1.24 & 3.21 & 1.65 & 558.50 & -0.96 & .336 \\
\hline Partner's authority & 3.70 & 1.47 & 3.72 & 1.97 & 637.50 & 0.06 & .950 \\
\hline $\begin{array}{l}\text { Argumentation and making } \\
\text { requests }\end{array}$ & 5.13 & 1.22 & 5.51 & 1.30 & 501.50 & 1.61 & .108 \\
\hline Persuasion and persistence & 4.14 & 1.15 & 4.10 & 1.28 & 621.00 & -0.25 & .803 \\
\hline Hard tactics & 2.70 & 0.94 & 2.25 & 0.94 & 465.00 & -2.01 & .044 \\
\hline Silent treatment and sulking & 2.91 & 1.18 & 2.43 & 1.28 & 487.50 & -1.76 & .078 \\
\hline Complaining and arguing & 3.73 & 1.54 & 2.95 & 1.45 & 450.00 & -2.19 & .029 \\
\hline Threats and violence & 1.45 & 0.50 & 1.38 & 0.75 & 477.50 & -1.93 & .054 \\
\hline
\end{tabular}

Note. A parametric $t$-test performed for variables characterized by normal distribution yielded identical results.

Table 5

Styles of self-presentation and tendency to adopt adonization of shy and non-shy men

\begin{tabular}{|c|c|c|c|c|c|c|c|}
\hline & \multicolumn{2}{|c|}{ Shy men } & \multicolumn{2}{|c|}{ Non-shy men } & \multirow[t]{2}{*}{$U$} & \multirow[t]{2}{*}{$Z$} & \multirow[t]{2}{*}{$p$} \\
\hline & M & $S D$ & $M$ & $S D$ & & & \\
\hline Self-promotion & 41.76 & 8.44 & 46.54 & 9.01 & 420.50 & 2.52 & .012 \\
\hline Self-depreciation & 43.97 & 8.23 & 36.51 & 8.57 & 328.50 & -3.56 & $<.001$ \\
\hline Adonization & 58.33 & 20.71 & 77.18 & 29.15 & 400.50 & 2.74 & .006 \\
\hline Cognitive component & 20.30 & 7.03 & 28.56 & 10.04 & 336.50 & 3.47 & $<.001$ \\
\hline Affective component & 18.03 & 6.97 & 23.97 & 9.14 & 394.50 & 2.81 & .005 \\
\hline Motivational component & 18.82 & 8.94 & 23.77 & 11.78 & 494.50 & 1.68 & .093 \\
\hline
\end{tabular}

Note. A parametric $t$-test performed for variables characterized by normal distribution yielded identical results. 
In close relationships, shy men are much less likely to adopt the Argumentation and making requests technique $(M=5.01)$, when compared to uninhibited men $(M=5.74, p=.026)$. Further, they exhibit a greater tendency to use Threats and violence $(M=1.70)$ when compared to non-shy men $(M=1.34, p=.043)$ (Table 6).

The study revealed a correlation between shyness and self-depreciation $(r=.46, p<.001)$ and self-promotion $(r=-.26, p<.001)$. It also demonstrated that with the increase in the level of shyness, the readiness to use adonization decreases $(r=-.25, p<.001)$. In close relationships, a higher level of shyness is connected with more frequent use of hard social influence tactics $(r=.15, p=.024)$ (Table 7).
A multiple regression analysis was performed using the enter method for variables remaining in strong correlations. Both shyness and the participants' gender proved to be significant predictors of the self-depreciation variable; $F(1,231)=37.76, p<.001$, accounting for $24 \%$ of its variance and the self-promotion variable; $F(1,231)=8.41, p<.001$, predicting $6 \%$ of its variance. Further, shyness and gender are predictors of the readiness to adopt adonization; $F(1,231)=13.94$, $p<.001$. They account for $10 \%$ of its variance. They are also predictors of using hard influence tactics in intimate relationships; $F(1,231)=5.09, p<.001$ and explain $3.4 \%$ of variance of the dependent variable. The regression model, in which the dependent vari-

Table 6

Influence tactics in close relationships as adopted by shy and non-shy men

\begin{tabular}{|c|c|c|c|c|c|c|c|}
\hline & \multicolumn{2}{|c|}{ Shy men } & \multicolumn{2}{|c|}{ Non-shy men } & \multirow[t]{2}{*}{$U$} & \multirow[t]{2}{*}{$Z$} & \multirow[t]{2}{*}{$p$} \\
\hline & M & $S D$ & M & $S D$ & & & \\
\hline Soft tactics & 3.70 & 0.85 & 3.52 & 1.01 & 543.00 & -1.13 & .258 \\
\hline Incompetence and hugging & 3.13 & 1.80 & 2.87 & 1.46 & 603.00 & -0.45 & .650 \\
\hline Bartering and favors & 3.34 & 1.13 & 3.17 & 1.31 & 553.00 & -1.02 & .308 \\
\hline Romanticism and surprises & 4.63 & 1.23 & 4.51 & 1.33 & 617.50 & -0.29 & .772 \\
\hline Medium tactics & 3.87 & 1.17 & 4.24 & 0.94 & 550.50 & 1.05 & .296 \\
\hline One's own authority & 3.36 & 1.68 & 3.59 & 1.62 & 585.00 & 0.66 & .510 \\
\hline Partner's authority & 3.42 & 1.55 & 3.59 & 1.75 & 623.00 & 0.23 & .820 \\
\hline $\begin{array}{l}\text { Argumentation and making } \\
\text { requests }\end{array}$ & 5.01 & 1.41 & 5.74 & 0.98 & 447.50 & 2.22 & .026 \\
\hline Persuasion and persistence & 3.68 & 1.34 & 4.03 & 1.27 & 526.50 & 1.32 & .187 \\
\hline Hard tactics & 2.20 & 1.09 & 1.99 & 0.85 & 582.00 & -0.69 & .490 \\
\hline Silent treatment and sulking & 2.08 & 1.04 & 1.89 & 0.92 & 591.00 & -0.59 & .554 \\
\hline Complaining and arguing & 2.83 & 1.55 & 2.74 & 1.51 & 622.50 & -0.23 & .816 \\
\hline Threats and violence & 1.70 & 1.11 & 1.34 & 0.56 & 469.50 & -2.03 & .043 \\
\hline
\end{tabular}

Note. A parametric $t$-test performed for variables characterized by normal distribution yielded identical results.

Table 7

Mean scores of study participants and correlations between the variables covered in the study

\begin{tabular}{|c|c|c|c|c|c|c|c|}
\hline Variables & $M(S D)$ & 1 & 2 & 3 & 4 & 5 & 6 \\
\hline 1. Shyness & $32.50(9.96)$ & - & & & & & \\
\hline 2. Self-promotion & $44.53(8.28)$ & $-.26^{* * *}$ & - & & & & \\
\hline 3. Self-depreciation & $40.83(8.22)$ & $.46^{* * *}$ & -.10 & - & & & \\
\hline 4. Adonization & $65.38(25.19)$ & $-.25^{* * *}$ & $.31^{* * *}$ & -.10 & - & & \\
\hline 5. Soft tactics & $3.72(1.04)$ & .04 & $.36^{* * *}$ & $.26^{* * *}$ & $.36^{* * *}$ & - & \\
\hline 6. Middle tactics & $4.16(1.02)$ & -.07 & $.34^{* * *}$ & .07 & $.34^{* * *}$ & $.56^{* *}$ & - \\
\hline 7. Hard tactics & $2.30(0.95)$ & $.15^{*}$ & $.27^{* * *}$ & $.24^{* * *}$ & $.26^{* * *}$ & $.46^{* * *}$ & $.52^{* * *}$ \\
\hline
\end{tabular}


Table 8

Shyness and gender as predictors of self-promotion, self-depreciation, adonization and hard influence tactics in close relationships - multiple regression analysis

\begin{tabular}{|c|c|c|c|c|c|c|c|}
\hline & $\beta$ & $B$ & $S E$ & $t$ & $p$ & $F$ & $R_{\text {adj }}^{2}$ \\
\hline \multicolumn{8}{|c|}{ Self-promotion } \\
\hline Gender & -.03 & -0.24 & 0.53 & -0.46 & .645 & \multirow{2}{*}{$8.41^{* * *}$} & \multirow{2}{*}{.06} \\
\hline Shyness & -.26 & -0.22 & 0.05 & -4.06 & $<.001$ & & \\
\hline \multicolumn{8}{|c|}{ Self-depreciation } \\
\hline Gender & -.18 & -1.51 & 0.47 & -3.22 & .001 & \multirow{2}{*}{$37.76^{* * *}$} & \multirow{2}{*}{.24} \\
\hline Shyness & .47 & 0.38 & 0.05 & 8.15 & $<.001$ & & \\
\hline \multicolumn{8}{|l|}{ Adonization } \\
\hline Gender & .21 & 5.37 & 1.56 & 3.43 & $<.001$ & \multirow{2}{*}{$13.94^{* * *}$} & \multirow{2}{*}{.10} \\
\hline Shyness & -.25 & -0.64 & 0.16 & -4.09 & $<.001$ & & \\
\hline \multicolumn{8}{|c|}{ Hard influence tactics in close relationships } \\
\hline Gender & -.14 & -0.14 & 0.06 & -2.23 & .027 & \multirow{2}{*}{$5.09^{* *}$} & \multirow{2}{*}{.03} \\
\hline Shyness & .15 & 0.01 & 0.01 & 2.34 & .020 & & \\
\hline \multicolumn{8}{|c|}{ Silent treatment and sulking } \\
\hline Gender & -.23 & -0.25 & 0.06 & -3.59 & $<.001$ & \multirow{2}{*}{$8.02^{* * *}$} & \multirow{2}{*}{.06} \\
\hline Shyness & .12 & 0.01 & 0.01 & 1.86 & .064 & & \\
\hline \multicolumn{8}{|c|}{ Complaining and arguing } \\
\hline Gender & -.15 & -0.22 & 0.10 & -2.29 & .023 & \multirow{2}{*}{$4.73^{* *}$} & \multirow{2}{*}{.03} \\
\hline Shyness & .14 & 0.02 & 0.01 & 2.11 & .036 & & \\
\hline \multicolumn{8}{|c|}{ Threats and violence } \\
\hline Gender & .09 & 0.07 & 0.05 & 1.39 & .165 & \multirow{2}{*}{2.93} & \multirow{2}{*}{.02} \\
\hline Shyness & .13 & 0.01 & 0.01 & 1.95 & .053 & & \\
\hline
\end{tabular}

Note. Gender coded: $1-\operatorname{man},-1-$ woman; ${ }^{*} p<.05,{ }^{* *} p<.01,{ }^{* * *} p<.001$.

able was the Silent treatment and sulking technique, proved to be adjusted to the data; $F(1,231)=8.02$, $p<.001$. It accounts for $5.7 \%$ of variance of the dependent variable. At the same time, shyness and gender are predictors of implementation of the Complaining and arguing tactic; $F(1,231)=4.73, p<.01$, explaining $3.1 \%$ of the variance of the dependent variable. Shyness was also identified as a predictor of use of the Threats and violence tactic; $F(1,231)=2.93, p<.055$. The model accounts for $1.6 \%$ of the variance of the dependent variable (Table 8 ).

\section{DISCUSSION}

The study investigated the relationship between shyness and self-presentation styles, the attitude towards adonization and the influence tactics in close relationships. The results showed that by using self-presentation shy individuals exhibit a tendency to self-de- preciate. They publicly belittle their accomplishments and capabilities by emphasizing their weakness, lack of competence and a possibility of failure. Presumably, the conviction that they are not able to create the desired impression makes them adopt behaviors that will prevent them from making a negative impression (Leary \& Kowalski, 2001). Such a strategy protects shy persons against being placed in the center of attention. Shy people become engaged in defensive self-presentation. The defensive nature of self-presentation minimizes the risk of rejection since it arouses considerable sympathy on the observer's side and ensures support in accordance with the norms of social responsibility (Jones \& Pittman, 1982). In the long term, however, this may cause social disapproval. It has been proven that self-depreciative utterances result in compatible behaviors in the addressee. When there is a prospect of more interactions with a person using self-depreciation techniques, the interlocutor starts to exhibit an inclination toward demonstrating 
his or her own weakness and, as a consequence, views the interaction negatively (Gergen \& Wishnow, 1965). It is presumably the norm of the positivity level, which obliges the people engaged in an interaction to reflect the interlocutor's expression that triggers the employment of complementary behaviors (Leary, 2012). This notion helps comprehend the interpersonal difficulties that shy people encounter. It should be stressed that self-depreciation entails the risk of accepting the low competence self-presented by an individual as factual information pertaining to this person's capabilities.

The investigated research findings are consistent with the results that reveal a connection between defensive self-presentation and a low self-esteem (Baumeister et al., 1989) and, in turn, a correlation between low self-esteem and shyness (Guangming, Qi, \& Hao, 2018). Shyness involves substantially less frequent use of assertive self-presentation in the form of self-promotion. At the same time, a positive self-presentation on the competence level increases a person's popularity in the social environment (Dufner et al., 2012). It also leads to positive consequences in terms of people's intrapsychic functioning. Studies have shown that an exaggerated attention devoted to abiding by the norm of modesty constitutes an obstacle for building one's self-esteem (Du \& Jonas, 2015). At the same time, the implications of modest behaviors in self-presentation are correlated with gender. A modest self-presentation may be effective for women but does not prove effective when adopted by men (Wosinska, Dabul, Whetstone-Dion, \& Cialdini, 1996; Dabul, Wosińska, Cialdini, Mandal, \& Dion, 1997). On the other hand, intentional self-enhancement that presents an individual as a better person compared to others obtains highly negative feedback from observers (Lafrenière, Sedikides, Van Tongeren, \& Davis, 2016).

The tendency revealed in the present research of shy individuals to self-depreciate has been proven to be used by both shy females and males. Due to the perpetuated gender stereotypes, self-depreciation is more socially accepted when it is employed by women than by men. Competence constitutes a vital dimension of the public image of a male (Leary et al., 1994) and hence it is likely that the image of shy males suffers more severely than that of shy females when they show their weakness.

Comparative analyses of the readiness to use adonization confirm men's overall higher readiness to adopt adonization, which was substantiated by previous research (Mandal, 2008b, 2014a). Shy men have a less favorable perception of their own appearance and taking advantage of it on a social level, and their emotional attitude towards exerting this sort of influence is negative. No significant discrepancies were found in the group of women. Shy females adopt adonization equally often as non-shy women do. An overall low readiness to use adonization among shy people may be considered from the point of view of behavioral inhibitions demonstrated by this group of people. Adonization requires selfconfidence and initiative.

The present results suggest that the implications associated with shyness may be more severe for males. Physical attractiveness of men maximizes their potential to achieve high social status in the reference group (Anderson, John, Keltner, \& Kring, 2001). At the same time, the role of physical attractiveness in social evaluation of women is less unambiguous. It often becomes an obstacle for women in their professional life, when applying for jobs that are stereotypically male-dominated (Johnson, Podratz, Dipboye, \& Gibbons, 2010; Isaac, Lee, \& Carnes, 2009). It also frequently implies attributing egoism, vanity, standoffishness, materialism, unfaithfulness and even low parental competence to very attractive women (Dermer \& Thiel, 1975). Physical attractiveness provides clear benefits for males while making the most of one's physical attractiveness when exerting influence is perceived as highly positive particularly from the standpoint of the opposite sex (Mandal et al., 2015). For this reason, a less pronounced readiness to use adonization by shy people may partially account for their difficulties on the interpersonal level.

The conducted analyses demonstrate a positive correlation between shyness and hard influence tactics in close relationships. Shy women exhibit the preference to adopt the following tactics when interacting with their partners: Complaining and arguing, Threats and violence, Silent treatment and sulking. On the other hand, when comparing shy men to non-shy men, the former group displays a greater tendency to employ the Threats and violence tactic. These results may be considered from the perspective of lower levels of social competence (Jackson et al., 1997) and emotional intelligence that may be ascribed to shy people (Hajloo \& Farajian, 2013). Difficulty in identifying one's feelings or emotional states of others as well as insufficient interpersonal skills justify the employment of hard influence tactics. This may be a potential source of problems, dissatisfaction or breakdown of an intimate relationship.

In the interpretation of the demonstrated correlation, the role of the family of origin where an individual learns social behaviors should not be downplayed. Research links parenting styles with shyness. In families that raise shy children parents may be overprotective, restrict their children's independence and interfere in their lives, while at the same time children experience a sense of distance and lack of interpersonal warmth (cf. Van Zalk \& Kerr, 2011; Tani, Porti, \& Smorti, 2014).

The notion of neurotic personality suggests that a neurotic personality is characterized by a high level of repressed hostility that vents while engaging in interpersonal relations. Shyness is defined as its external manifestation that inhibits the experience of 
intimacy in close relationships while at the same time serving as a protection against rejection that is frequently the result of the adopted techniques of exerting influence that are uncomfortable for the interlocutor (Horney, 1937).

Shyness has profound consequences both in terms of an individual's functioning on a social level and in the context of the dynamics of interpersonal close relationships.

\section{CONCLUSIONS}

The study extends knowledge of the social activity of shy people. The findings indicate that shy individuals exhibit behaviors that are less effective and less pleasant for others to experience. Shyness limits the repertoire of positive social behaviors. Further, the results reveal discrepancies between genders. On the one hand, the perpetuated stereotype of a shy woman is likely to increase social acceptance of certain behaviors that stem from shyness. On the other hand, men seem to have to bear higher psychological costs of shyness.

\section{LIMITATIONS}

It must be noted that the present research findings do not reflect the entire complexity of the notion of shyness, treating shy persons as a homogeneous study group. It would seem viable to take into consideration additional variables such as sociability (shy sociable and shy unsociable persons) (Cheek \& Buss, 1981) or self-awareness (privately shy and publicly shy individuals) (Pilkonis, 1977b).

Investigation into exerting influence in close relationships requires taking into consideration additional important aspects of an intimate relationship, such as the nature of the relationship, its length, partners' age, partners' children, relationship satisfaction or partners' personalities, among others. As participants were adolescents as well as young adults approaching transition to middle adulthood, it would be recommendable to consider the diversity of experiences in close relationships depending on age. It might seem interesting to extend the group of participants to include not only young adults but also middle-aged and older adults too.

\section{References}

Anderson, C., John, O. P., Keltner, D., \& Kring, A. M. (2001). Who attains social status? Effects of personality and physical attractiveness in social groups. Journal of Personality and Social Psychology, 81, 116132. https://doi.org/10.1037//0022-3514.81.1.116
Asendorph, J. B. (1988). Individual response profiles in the behavioral assessment of personality. European Journal of Personality, 2, 155-167. https://doi. org/10.1002/per.2410020209

Asendorph, J. B. (1990). The expression of shyness and embarrassment. In W. R. Crozier (Ed.), Shyness and embarrassment: Perspectives from social psychology (pp. 87-118). New York: Cambridge University Press.

Baumeister, R. F., Tice, D. M., \& Hutton, D. G. (1989). Self-presentational motivations and personality differences in self-esteem. Journal of Personality, 56, 547-579. https://doi.org/10.1111/j.1467-6494.1989. tb02384.x

Baumgardner, A. H., Kaufman, C. M., \& Levy, P. E. (1989). Regulating affect interpersonally: When low esteem leads to a greater enhancement. Journal of Personality and Social Psychology, 56, 907-921. https://doi.org/10.1037/0022-3514.56.6.907

Bratko, D., Vukosav, Ž., Zarevski, P., \& Vranić, A. (2002). The relations of shyness and assertiveness traits with the dimensions of the five-factor model in adolescence. Review of Psychology, 9, 17-23.

Bruch, M. A., Berko, E. H., \& Haase, R. F. (1998). Shyness, masculine ideology, physical attractiveness, and emotional inexpressiveness: Testing a mediational model of men's interpersonal competence. Journal of Counseling Psychology, 45, 84-97. https://doi.org/10.1037/0022-0167.45.1.84

Brzezińska, A., Appelt, K., \& Ziółkowska, B. (2016). Psychologia rozwoju człowieka [The psychology of human development]. Sopot: GWP.

Buss, D. M. (1992). Manipulation in close relationships: Five personality factors in interactional context. Journal of Personality, 60, 477-499. https:// doi.org/10.1111/j.1467-6494.1992.tb00981.x

Buss, A. H., \& Briggs, S. R. (1984). Drama and the Self in social interaction. Journal of Personality and Social Psychology, 47, 1310-1324. https://doi. org/10.1037/0022-3514.47.6.1310

Carducci, B. J. (2008). Nieśmiatość. Nowe odważne podejście [Shyness: A bold new approach]. Cracow: Znak.

Carli, L. L. (2001). Gender and social influence. Journal of Social Issues, 57, 725-741. https://doi.org/10. 1111/0022-4537.00238

Chaiken, S. (1979). Communicator physical attractiveness and persuasion. Journal of Personality and Social Psychology, 37, 1387-1397. https://doi. org/10.1037/0022-3514.37.8.1387

Cheek, J. M. (1983). The Revised Cheek and Buss Shyness Scale (RCBS). Unpublished manuscript. Wellesley, MA: Wellesley College.

Cheek, J. M., \& Briggs, S. R. (1990). Shyness as a personality trait. In W. R. Crozier (Ed.), Shyness and embarrassment: Perspectives from social psychology (pp. 315-337). New York: Cambridge University Press.

Cheek, J. M., \& Buss, A. H. (1981). Shyness and sociability. Journal of Personality and Social Psychology, 41, 330-339. https://doi.org/10.1037/0022-3514.41.2.330 
Cheek, J. M., \& Watson, A. K. (1989). The definition of shyness: Psychological imperialism or construct validity? Journal of Social Behaviour and Personality, 4, 85-95.

Crozier, W. R. (1979). Shyness as a dimension of personality. British Journal of Social and Clinical Psychology, 18, 121-128. https://doi.org/10.1111/j. 2044-8260.1979.tb00314.x

Crozier, W. R. (1981). Shyness and self-esteem. British Journal of Social Psychology, 20, 220-222. https:// doi.org/10.1111/j.2044-8309.1981.tb00537.x

Dabul, A. J., Wosińska, W., Cialdini, R. B., Mandal, E., \& Dion, R. W. (1997). Self-presentational modesty across cultures: The effects of gender and social context in the workplace. Polish Psychological Bulletin, 28, 295-307.

Dermer, M., \& Thiel, D. L. (1975). When beauty may fail. Journal of Personality and Social Psychology, 31, 1168-1176. https://doi.org/10.1037/h0077085

Dion, K., Berscheid, E., \& Walster, E. (1972). What is beautiful is good. Journal of Personality and Social Psychology, 24, 285-290. https://doi.org/10.1037/ h0033731

Du, H., \& Jonas, E. (2015). Being modest makes you feel bad: Effects of the modesty norm and mortality salience on self-esteem in a collectivistic culture. Scandinavian Journal of Psychology, 56, 86-98. https://doi.org/10.1111/sjop. 12175

Dufner, M., Denissen, J. J., van Zalk, M., Matthes, B., Meeus, W. H. J., van Aken, M. A. G., \& Sedikides, C. (2012). Positive intelligence illusions: On the relation between intellectual self-enhancement and psychological adjustment. Journal of Personality, 80, 537572. https://doi.org/10.1111/j.1467-6494.2011.00742.x

Dzwonkowska, I. (2003). Nieśmiałość i jej korelaty [Shyness and its correlates]. Przegląd Psychologiczny, 46, 307-322.

Falbo, T. (1977). Multidimensional scaling of power strategies. Journal of Personality and Social Psychology, 35, 537-547. https://doi.org/10.1037/0022-3514.35.8.537

Felmlee, D. H. (1994). Who's on top? Power in romantic relationships. Sex Roles, 31, 275-295. https:// doi.org/10.1007/BF01544589

Gergen, K. J., \& Wishnow, B. (1965). Others' selfevaluations and interaction anticipation as determinants of self-presentation. Journal of Personality and Social Psychology, 2, 348-358. https://doi. org/10.1037/h0022385

Goffman, E. (1959). The presentation of self in everyday life. New York: Anchor Books Ed.

Guangming, R., Qi, Z., \& Hao, H. (2018). Behavioral inhibition system and self-esteem as mediators between shyness and social anxiety. Psychiatry Research, 270, 568-573. https://doi.org/10.1016/j.psychres.2018.10.017

Hajloo, N., \& Farajian, A. (2013). Relationship between emotional intelligence and shyness. Procedia - Social and Behavioral Science, 84, 1180-1183. https://doi.org/10.1016/j.sbspro.2013.06.723
Harwas-Napierała, B. (1995). Nieśmiatość dorostych. Geneza. Diagnostyka. Terapia [Shyness in adults. Genesis. Diagnostics. Therapy]. Poznań: Wydawnictwo Fundacji Humaniora.

Heiser, N. A., Turner, S. M., \& Beidel, D. C. (2003). Shyness: relationship to social phobia and other psychiatric disorders. Behavior Research and Therapy, 41, 209221. https://doi.org/10.1016/S0005-7967(02)00003-7

Henderson, L. M., Zimbardo, P. G., \& Carducci, B. J. (2001). Shyness. In C. Nemeroff \& W. E. Craighead (Eds.), The Corsini encyclopedia of psychology and behavioral science (Vol. 4, pp. 1522-1523). New York: John Wiley \& Sons, Inc.

Hopko, D. R., Stowell, J., Jones, W. H., Armento, M. E. A., \& Cheek, J. M. (2005). Psychometric properties of the Revised Cheek and Buss Shyness Scale. Journal of Personality Assessment, 84, 185-192. https://doi. org/10.1207/s15327752jpa8402_08

Horney, K. (1937). The neurotic personality of our time. New York: Norton.

Howard, J. A., Blumstein, P., \& Schwartz, P. (1986). Sex, power, and influence tactics in intimate relationships. Journal of Personality and Social Psychology, 51, 102-109. https://doi.org/10.1037/0022-3514.51.1.102

Isaac, C., Lee, B., \& Carnes, M. (2009). Interventions that affect gender bias in hiring: A systematic review. Academic Medicine: Journal of the Association of American Medical Colleges, 84, 1440-1446. https://doi.org/10.1097/ACM.0b013e3181b6ba00

Jackson, T., Towson, S., \& Narduzzi, K. (1997). Predictors of shyness: A test of variables associated with self-presentational models. Social Behavior and Personality, 25, 149-153. https://doi.org/10.2224/ sbp.1997.25.2.149

Johnson, S. K., Podratz, K. E., Dipboye, R. L., \& Gibbons, E. (2010). Physical attractiveness biases in ratings of employment suitability: Tracking down the 'Beauty is beastly' effect. The Journal of Social Psychology, 150, 301-318. https://doi.org/10.1080/ 00224540903365414

Jones, E. E., \& Pittman, T. S. (1982). Toward a general theory of strategic self-presentation. In J. Suls (Ed.), Psychological perspectives on the self (Vol.1, pp. 231-262). Hillsdale, NJ: Erlbaum.

Lafrenière, M. A., Sedikides, C., Van Tongeren, D. R., \& Davis, J. (2016). On the perceived intentionality of self-enhancement. The Journal of Social Psychology, 156, 28-42. https://doi.org/10.1080/002245 45.2015.1041447

Leary, M. R. (2012). Wywieranie wrażenia na innych. $O$ sztuce autoprezentacji [Self presentation: Impression management and interpersonal behavior]. Gdańsk: GWP.

Leary, M. R., \& Kowalski, R. R. (2001). Lęk spoteczny [Social anxiety]. Gdańsk: GWP.

Leary, M. R., Nezlek, J. B., Downs, D., Radford-Davenport, J., Martin, J., \& McMullen, A. (1994). Selfpresentation in everyday interactions: effects on target familiarity and gender composition. Journal 
of Personality and Social Psychology, 67, 664-673. https://doi.org/10.1037//0022-3514.67.4.664

Longo, L. C., \& Ashmore, R. D. (1992). The perceived relationship between physical attractiveness and social influence effectiveness. Paper presented at the Annual Convention of the American Psychological Association (100th, Washington, DC, August 14-18, 1992).

Mandal, E. (2003). Social influence strategies of Polish and Macedonian men and women in the workplace - the effects of profit and loss situations, gender, and culture. Polish Psychological Bulletin, 34, 37-45.

Mandal, E. (2008a). Shyness and gender. Physical, emotional, cognitive, behavioral consequences and strategies of coping with shyness by women and men of different gender identity. The New Educational Review, 14, 259-273.

Mandal, E. (2008b). Miłość, władza i manipulacja w bliskich zwiqzzach [Love, power and manipulation in close relationships]. Warsaw: PWN.

Mandal, E. (2012). Władza i wywieranie wpływu w bliskich związkach [Power and exerting influence in close relationships]. Chowanna, 3, 149-165.

Mandal, E. (2014a). Beauty and social influence. Adonization and its correlates. Polish Psychological Bulletin, 45, 80-91. https://doi.org/10.2478/ppb-2014-0012

Mandal, E. (2014b). Kwestionariusz wywierania wpływu w bliskich związkach kobiet i mężczyzn [The Influence in Close Relationships between Women and Men Questionnaire]. Przegląd Psychologiczny, 57, 193-211.

Mandal, E., Latusek, A., \& Moroń, M. (2015). Oczarować i przekonać. Postrzeganie osób wykorzystujących fizyczną atrakcyjność w wywieraniu wpływu na innych [To enthral and persuade. The perception of persons who employ physical attractiveness when exerting social influence]. In E. Mandal \& D. Doliński (Eds.), Wptyw spoteczny w sytuacjach codziennych $i$ niecodziennych [Social influence in everyday and unusual situations] (pp. 17-45). Warsaw: PWN.

Mandal, E., \& Wierzchoń, A. (2018). Revised Cheek and Buss Shyness Scale (RCBS) (Cheek, 1983; Hopko, Stowell, Jones, Armento \& Cheek, 2005; Polish adaptation). Katowice: Institute of Psychology, University of Silesia.

Mandal, E., \& Winkler, M. (2005). Kwestionariusz do pomiaru postawy wobec adonizacji. Skala A [Questionnaire for measuring the attitude toward adonization - Scale A]. Katowice: Institute of Psychology, University of Silesia.

Pilkonis, P. A. (1977a). The behavioral consequences of shyness. Journal of Personality, 45, 596-611. https:// doi.org/10.1111/j.1467-6494.1977.tb00174.x

Pilkonis, P. A. (1977b). Shyness, public and private, and its relationship to other measures of social behavior. Journal of Personality, 45, 585-595. https://doi. org/10.1111/j.1467-6494.1977.tb00173.x

Ponti, L., \& Tani, F. (2015). Shyness and psychological adjustment: The moderating role of friendship relationship. Journal of Psychopathology, 21, 30-39.
Schlenker, B. R., \& Leary, M. R. (1982). Social anxiety and self-presentation: $A$ conceptualization and model. Psychological Bulletin, 92, 641-669. https:// doi.org/10.1037/0033-2909.92.3.641

Schlenker, B. R., \& Weigold, M. F. (1992). Interpersonal processes involving impression regulation and management. Annual Review of Psychology, 43, 133-168. https://doi.org/10.1146/annurev.ps.43.020192.001025

Sijko, K. (2008). Jak grają pary? Dynamika wpływu społecznego w bliskich związkach [How do couples play? Dynamics of social influence in close relationships]. Psychologia Jakości Życia, 7, 139-157.

Sundie, J., Cialdini, R. B., Griskevicius, V., \& Kenrick, D. T. (2012). The world's (truly) oldest profession: Social influence evolutionary perspective. Social Influence, 7, 134-153. https://doi.org/10.1080/15 534510.2011 .649890

Tackett, S. L., Nelson, L. J., \& Busby, D. M. (2013). Shyness and relationship satisfaction: Evaluating the associations between shyness, self-esteem, and relationship satisfaction in couples. The American Journal of Family Therapy, 41, 34-45. https://doi.org/ 10.1080/01926187.2011.641864

Tani, F., Porti, L., \& Smorti, M. (2014). Shyness and psychological adjustment during adolescence: The moderating role of parenting style. The Open Psychology Journal, 7, 33-44. https://doi.org/10.2174/ 1874350101407010033

Tice, D. M. (1992). Self-concept change and self-presentation: The looking glass self is also a magnifying glass. Journal of Personality and Social Psychology, 63, 435-451. https://doi.org/10.1037/0022-3514.63.3.435

Van Zalk, N., \& Kerr, M. (2011). Shy adolescents' perceptions of parents' psychological control and emotional warmth: Examining bidirectional links. Merril-Palmer Quarterly, 57, 375-401. https://doi. org/10.1353/mpq.2011.0021

Van Zalk, N., Lamb, M. E., \& Rentfrow, P. J. (2017). Does shyness vary according to attained social roles? Trends across age groups in a large British sample: Shyness trends. Journal of Personality, 85, 830-840. https://doi.org/10.1111/jopy. 12291

Wojciszke, B. (2002). Autopromocja i autodeprecjacja. Kwestionariusz Stylów Autoprezentacji [Selfpromotion and Self-deprecation. The Self-Presentation Questionnaire]. Psychologia Jakości Życia, 1, 145-171.

Wosinska, W., Dabul, A. J., Whetstone-Dion, R., \& Cialdini, R. B. (1996). Self-presentational responses to success in the organization: The costs and benefits of modesty. Basic and Applied Social Psychology, 18, 229-242. https://doi.org/10.1207/s15324834 basp1802_8

Zimbardo, P. G. (1994). Nieśmiatość. Co to jest? Jak sobie z niq radzić? [Shyness: What it is? What to do about it?]. Warsaw: PWN.

Zimbardo, P. G., Pilkonis, P. A., \& Norwood, R. M. (1974). The silent prison of shyness. Office of Naval Research Tech, Rep. Z-17, Stanford University. 